\title{
Prevalence of human papillomavirus (HPV) in the oral cavity of children and adolescents - what should dentists know?
}

\author{
Dorota Polz-Gruszka ${ }^{1}{ }_{\text {ABDEFG }}$ Jerzy Błaszczak ${ }_{\text {ABDEFG}}^{2}$ Maria Mielnik-Błaszczak ${ }_{\text {ABDEFG }}^{2}$ Małgorzata Polz-Dacewicz ${ }_{\text {ABDEFG }}^{1}$ \\ ${ }^{1}$ Department of Virology, Medical University of Lublin \\ ${ }^{2}$ Chair and Department of Paedodontics, Medical University of Lublin
}

Summary

Human papillomavirus (HPV) belongs to oncogenic viruses and associated with the development of many pathologies within the oral cavity and pharynx, including oropharyngeal squamous cell carcinoma. The aim of the study was to introduce dentists to HPV-related issues in the oral cavity of children and adolescents.

Key words: human papillomavirus (HPV), oropharyngeal squamous cell carcinoma, children

Human papillomavirus (HPV) belongs to the group of oncogenic viruses and is increasingly well known. HPV is most commonly mentioned in the context of cervical cancer. Dentists however should remember that HPV is associated with the development of oropharyngolaryngeal squamous carcinoma. It is an epitheliotropic virus, i.e. shows affinity and multiplies in the differentiating stratified squamous epithelium. It is sexually transmitted yet this is not the only route of its transmission. The aim of the present study was to introduce dentists to the issues of HPV infections in children, i.e. the group that the least attention is devoted to.

High-risk types (HR) are detected in cancers of the cervix, rectum, penis, vagina, oral cavity and pharynx. Low-risk HPVs are responsible for benign papillomatous lesions-dermal papillae, genital papillae, respiratory papillomatosis, nasal-oral papilloma [1].

Many factors are undoubtedly involved in the development of oropharyngeal squamous cell carcinoma, of which tobacco smoking and alcohol abuse are best known. Moreover, it predominantly occurs (5-70\%) in male patients aged 60-70 years [2]. It is however increasingly detected in young patients [2,3], who do not smoke or abuse alcohol. In this group the most likely factor causing the disease is HPV infection. Vidotti et al. [4] observed HPV in the oral cavity of young women (below the age of 30 years). HPV is one of the frequently sexually transmitted viruses (STD). This is obviously not the only route of transmission and the issue of such infections regards children as well. Since the virus in question is involved in the development of pathologies localized in the oropharynx, i.e. the area dentists are interested in, and is detected in increasingly young patients, it is worthy to describe the current reports concerning this subject. Furthermore, oral cytology is of growing diagnostic importance, therefore, the issue is extremely important for dentists.

The most common HPV infection-related pathologies in children are oral papillomas (7.5\%), although HPV DNA is also found in children with the he- althy mucosa [5]. Syrjänen et al. [6] distinguished the following routes of HPV transmission amongst children (1) non-sexual - directly (person-to-person, auto-inoculation), indirectly (via contaminated objects, contaminated surfaces) (2) maternal: directly (during vaginal delivery, Caesarean section/early rupture of membranes, from mother when taking care of the baby, likely via breast milk and saliva), indirectly (during vaginal delivery via contaminated objects or surfaces, Caesarean section, via contaminated object and surfaces), in utero (through semen, ascending infection from the mother's genital tract, transplacentally) (3) sexual abuse. Mammas et al. [7] examined 190 children aged 2-14 years (mean age 7 years). HPV DNA was detected in $8.4 \%$ of cases. The most commonly found virus was HPV 16, i.e. HR type. The authors did not demonstrate the correlation between the presence of HPV DNA and the type of delivery (normal vaginal delivery or Caesarean section). Interestingly, amongst the youngest patients, type 11 of LR was dominant, responsible for the development papillomas in children born by normal vaginal delivery. Martinelli et al. [8] studied 177 children aged 0-6 months (mean 3 months) collecting swabs from their oral cavity and pharynx. HPV DNA was detected in $14.1 \%$ of samples. They identified 8 genotypes, both of low and high risk -HPV 16, 18, 31, 33, 58 (mucosal HR-HPV), 81,84 (mucosal LR HPV) and 27 (cutaneous genotype). The authors suggested that the infection was likely to be transmitted from mothers to children during delivery and that dermal types could be transmitted by everyday contact or via contaminated objects.

The Polish study by Tarka et al. [9] focused on the risk of infection transmission during the perinatal period. The authors examined 185 pregnant women by collecting cervical swabs and swabs from the oral cavity of newborns. During the next stage of the study, 3-6 months later, cervical swabs were re-collected from patients HR HPV positive ( 28 patients, i.e. 15.1\%) and oral and nasopharyngeal swabs were taken from their 
children. Chronic infections were confirmed in $89.2 \%$ of $\mathrm{HPV}$ - infected patients; during the first study stage, HR HPV DNA was detected in 2\% of children whereas 3-6 months later in $1 \%$. The authors concluded that the risk of HR HPV transmission in the perinatal period from mothers to children was low.

Durzyńska et al. [10] carried out the study in the population of children and adolescents in Poland. In total 4150 children aged 10-18 years were examined. HPV DNA was detected in $1.08 \%$ of cases; however, no HR genotype was found. So low detectability can be caused by two factors: low prevalence of the virus in the population studied or the methods used - samples were rinsed with a saline solution while in the majority of other studies swabs were collected from the mucosa. HPV is an epitheliotropic virus; therefore, its detection is more likely in swabs/biopsies than in washings.

Yoshida et al. [11] analysed the risk of HR HPV transmission from mothers to children during breast feeding. They examined 80 maternal milk samples. HPV 16 was detected in $2.5 \%$ of samples, no virus was found in breast-fed children. Based on the findings the authors concluded that this route infection transmission is highly unlikely, albeit not impossible. Prevalence of HPV-related squamous cell carcinoma increases and this upward tendency is likely to maintain in Europe and America. The method facilitating the diagnosis, which can be performed by dentists, is cytology. It can be performed in the unaffected mucosa, leukoplakia, erythropakia in which HPV infection increases the risk of cancer development from the squamous cell carcinoma. [12] HPV is also associated with squamous papilloma, condyloma acuminata, focal epithelial hyperplasia, lichen planus, pemphigus vulgaris [13]; in future, it can be also possible to collect the cell material from those lesions.

\section{Conclusions}

The role of HPV in the development of oral pathologies is essential; considering the current knowledge, the importance of infection in the paediatric population it cannot be conclusively determined; nevertheless, dentists should have proper knowledge regarding this issue and pay attention to lesions located in the mucous membranes.

\section{References:}

1. Pytynia K, Dahlstrom K, Strugis E. Epidemiology of HPV-associated oropharyngeal cancer. Oral Oncol. 2014; 50: 380-386.

2. Van Monsjou H, Wreesmann V, Van den Brekel M, Balm A. Head and neck squamous cell carcinoma in young patients. Oral Oncol. 2013; 49: 1097-1102.

3. Golusiński W, Waśniewska E, Kaczmarek J, Kedzia D, Wróbel D, Wróbel M, Malinowska B. Retrospektywna, wieloczynnikowa analiza raków płaskonabłonkowych głowy i szyi. Otolaryngologia Pol. 2003; 57: 185-189.
4. Vidotti L, Castello Branco Vidal F, Moutinho Monteiro S, Nunes J, Saldago J, Oliveira Brito L, Ferreira Lopes F. Association between oral DNA-HPV and genital DNA -HPV. J Oral Pathol Med. 2014; 43: 289-292.

5. Syrjänen S. Current concepts on human papillomavirus infecions in childern. APMIS. 2010; 118: 494-509. 6. Syrjänen S, Puranen M. Human papillomavirus infection in children: the potential role of maternal transmission. Crit Rev Oral Biol Med. 2000; 11(2): 259-274.

7. Mammas IN, Sourvinos G, Giamarelou P, Michael C, Spandidos DA. Human papillomavirus In the oral cavity of childern and mode of delivery:a retrospective study. Int J STD AIDS. 2012; 23(2): 185-188.

8. Martinelli M, Zappa A, Bianchi S, Frati E, Colzani D. Amendola A., Tanzi E. Human papillomavirus (HPV) infection and genotype frequency in the oral mucosa of newborns in Milan, Italy. Clin Microbiol Infect. 2012; 18(6): 197-199.

9. Tarka ., Szczepańska M, Rokita W, Józefiak A., Kędzia W. Risk assessment of chronic HPV HR infectionin babies who contacted the virus in perinatal period. Ginekol Pol. 2011; 82(9): 664-669.

10. Durzyńska J, Pacholska-Bogalska J, Kaczmarek M, Hanć T, Durda M, Skrzypczak M, Goździcka-Józefiak A. HPV genotypes in the oral cavity/oropharynx of children and adolescents: cross-sectional survey in Poland. Eur J Pediatr. 2011; 170: 77-761.

11. Yoshida K, Furumoto H, Abe A, Kato T, Nishimura M, Kuwahara A, Maeda K, Matsuzki T, Irahara M. The possibility of vertical transmission of human papillomavirus through maternal milk. J Obstet Gynaecol. 2011; 31(6): 503-506.

12. Dona M, Giuliani M, Vocaturo A, Spriano G, Pichi B, Rollo F, Ronchetti L, Covello R, Pescarmona E, Benevolo M. Cytology and Human papillomavirus testing on cytobrushing samples from patients with head and neck squamous cell carcinoma. Cancer 2014 doi:10.1002/ cncr.28909.

13. Pinheiro R, Ribeiro de Franca T, Rocha B, Calvaro Ferreira D, Bender Ribeiro C, Cavalcani S, Ribeiro de Souza I, Carneiro Leao J, Barbosa Castro G. Human papillomavirus coinfection in the oral cavity of HIV-infected children. J Clin Pathol. 2011; 64: 1083-108.

\author{
Correspondence address: \\ Dorota Polz-Gruszka PhD \\ Department of Virology \\ Medical University in Lublin \\ ul. Chodźki 1 \\ 20-816 Lublin \\ dorotapolz@umlub.pl
}

